\title{
TRANSFORMASI HIDUP PADA TOKOH-TOKOH GEREJA
}

\author{
Agus Widodo
}

\begin{abstract}
:
Human life never stops. It continuously changing, physically, mentally and spiritually. Physical changes are influenced by food, beverages, and various physical activities. Meanwhile, mental and spiritual changes are affected by our intellect and liberty with which, human being are able to consider, choose and decide. Therefore, mental and spiritual changes in a person are not merely natural, spontaneous and automatic process. It is a transformation that includes: change of heart, mind, willingness and attitude or action. For sure, the desired transformation is the one which is from bad to good, or from good to better. Therefore, the transformation itself covers changes from bad into good and into better. But, how can we transform ourselves? One way of transformation is to learn from the saints, historical figures in the Catholic Church who have transformed their lives in grace and Christian discipleship.
\end{abstract}

\section{Kata-kata Kunci:}

Transformasi hidup, tokoh Gereja, pengalaman, kisah, spiritual, pertobatan/bertobat.

\section{APA DAN MENGAPA TRANSFORMASI HIDUP}

Sebelum berbicara tentang transformasi hidup dengan belajar pada beberapa tokoh Gereja di sepanjang sejarah untuk kemudian mengambil inspirasi dari mereka, secara singkat akan disampaikan terlebih dahulu tentang apa dan mengapa transformasi hidup. Dalam Kamus Bahasa Indonesia, "transformasi" (trans.for.ma.si) berarti perubahan rupa (bentuk, sifat, fungsi, dsb). ${ }^{1}$ Kata tersebut mempunyai akar dari bahasa latin transformatio yang berasal dari dua kata dasar trans dan forma. Trans berarti: menyeberangi, melintasi atau melampaui; forma berarti: rupa, bentuk atau wujud. ${ }^{2}$ Dengan demikian, "transformasi" dapat diartikan sebagai perubahan rupa, bentuk, wujud atau fungsi sehingga merupakan suatu perubahan yang melampaui dari sekedar sisi luaran saja. Sementara itu, kata "hidup", dapat dijelaskan berdasarkan terminologi Yunani yang

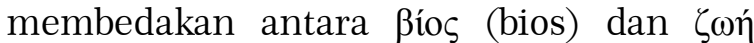
(zoe). Kata bios dipakai untuk menunjukkan kehidupan biologis yang dipelihara dan dipertahankan dengan makanan, minuman dan udara tetapi pada suatu saat berakhir dengan kematian. Sedangkan kata zoe, dan inilah yang dimaksudkan dalam tulisan ini, menunjukkan kehidupan rohani yang khas manusia dan bersifat kekal. Berdasarkan penjelasan di atas, transformasi hidup dapat dimaknai sebagai perubahan mental dan spiritual seseorang dari cara hidup lama yang kurang baik menjadi baik atau 
lebih baik, yang meliputi baik perubahan hati, pikiran, keinginan atau kehendak dan tingkah laku. Secara teologis, istilah transformasi hidup sebagaimana dijelaskan di atas dapat disamakan dengan "pertobatan", yakni perubahan hati dan pikiran yang diikuti dengan perubahan karakter, prilaku, sikap dan perbuatan di mana kita memalingkan diri dari dosa untuk berbalik kepada Tuhan dan dengan demikian kita semakin terbuka pada rahmat-Nya yang memampukan kita untuk menjadi semakin dekat dan mencintai-Nya. Inilah yang dikatakan oleh St. Paulus dengan meninggalkan manusia lama dan mengena-kan manusia baru, "kamu telah menang-galkan manusia lama serta kelakuannya, dan telah mengenakan manusia baru yang terus-menerus diperbaharui untuk memperoleh pengetahuan yang benar menurut gambar Khaliknya" (Kol 3: 9-10).

Berkaitan dengan mengapa orang harus bertobat atau mentransformasi hidupnya dari tidak baik menjadi baik dan semakin lebih baik lagi, setidaknya ada dua alasan. Yang pertama, pertobatan adalah jawaban kita atas panggilan dan kehendak Tuhan yang ingin menyelamatkan kita, "Bertobatlah, sebab Kerajaan Sorga sudah dekat!" (Mat 4: 17) dan "sesungguhnya jika kamu tidak bertobat ..., kamu tidak akan masuk ke dalam Kerajaan Sorga" (Mat 18: 3). Jadi, bertobat merupakan prasayarat yang mutlak untuk diselamatkan atau untuk memasuki kehi-dupan kekal dalam Kerajaan Sorga. Keselamatan adalah karya Tuhan dan Ia dapat memperuntukkannya bagi siapa saja, demikian pula sorga adalah milik Tuhan dan Ia dapat memberikan kepada siapa saja. Dan Ia menjelaskan kepada kita bahwa satu-satunya cara untuk mendapatkan anugerah keselamatan dan Kerajaan Sorga tersebut adalah dengan bertobat, dengan berpaling dari dosa dan berbalik kepadaNya. Yang kedua, kita tahu bahwa dosa dan kejahatan tidak hanya merusak hubungan kita dengan Tuhan tetapi juga dengan sesama bahkan sangat merugikan dan menghancurkan kehidupan orang lain, sehingga pertobatan amat diperlukan untuk memperbaiki relasi dengan sesama dan dengan demikian juga amat penting untuk menciptakan kehidupan bersama yang harmonis. Oleh karena itu, melalui para nabi Tuhan pun mendesak kita, "Berhentilah berbuat jahat, belajarlah berbuat baik" (Yes 1: 16b-17).

\section{TRANSFORMASI HIDUP PADA BEBERAPA TOKOH GEREJA}

Beberapa tokoh yang kisah hidupnya akan diuraikan dalam tulisan ini adalah: $S t$. Paulus ( $\pm 5-67)$, St. Agustinus (354-430), St. Ignatius Loyola (1491-1556), St. Theresia Avila (1515-1582), Edith Stein (1891-1942), Dorothy Day (1897-1980), dan Thomas Merton (1915-1968). Mereka ini dipilih karena kisah hidupnya menunjukkan transformasi dengan sangat jelas, baik dilihat dari sisi perubahannya sendiri maupun dari sisi faktor atau sarana yang menyebabkan atau membantu terjadinya pengubahan tersebut secara berhasil.

\section{St. Paulus $( \pm 5-67)$}

Paulus adalah figur besar dalam tradisi kekristenan, terutama karena perannya sebagai misionaris pioner yang membawa warta Yesus Kristus ke luar Palestina. Sebelum menjadi Kristen, Paulus bernama Saulus. Ia berasal dari Tarsus, sebuah kota di Sisilia yang mayoritas penduduknya adalah orang Yunani. Orangtuanya yang beragama Yahudi - kendati berkewarganegaraan Romawi dan lebih fasih berbahasa Yunani - memberikan pendidikan agama dan adat-istiadat Yahudi yang kuat sejak Saulus masih kecil. Bahkan, mereka mengirim Saulus untuk mengenyam pendidikan agama Yahudi di Yerusalem sehingga ia tumbuh menjadi orang Farisi yang sangat militan, baik dalam menguasai maupun mentaati Taurat dan aturanaturan keagamaan lainnya. Sekem-balinya dari Yerusalem, Saulus menjadi pembuat dan penjual tenda di Tarsus serta menjadi aktivis Farisi dalam membina iman orangorang Yahudi di Tarsus dan sekitarnya. Maka, ketika mendengar bahwa beberapa orang Yahudi di Israel menjadi pengikut Kristus, ia menilai bahwa mereka telah murtad dari agama Yahudi sehingga harus ditekan, dikejar, dianiaya dan dipenjara (Kis 9:1). 
Dalam perjalanannya ke Damsyik untuk melaksanakan misinya tersebut, Saulus memperoleh pengalaman rohani yang mengubah seluruh arah dan semangat hidupnya. Ia berjumpa dengan Tuhan Yesus dan menerima perutusan dari-Nya. Namun, proses transformasi hidup Paulus kiranya tidak berlangsung secara cepat dan begitu saja, yaitu segera dan otomatis setelah ia mengalami dengan Yesus. Setelah peristiwa itu, Paulus dibaptis di Damsyik dan kemudian pergi ke Arab. Di sanalah, mungkin ia merenungkan makna terdalam dari penga-laman rohaninya tersebut sehingga dalam perjalanan hidup selanjutnya ia dapat menghayati dan membagikan makna yang begitu kaya dan mendalam atas pengala-mannya itu.

Dalam suratnya kepada Jemaat Galatia, Paulus mengartikan pengalaman Damsyik tersebut sebagai pengalaman pewahyuan dan perutusan. Ia menyatakan bahwa Allah "telah memilih ... memanggil ... menyatakan Anak-Nya ... supaya [Paulus] memberitakan Dia ..." (Gal 1:15-16). Dengan demikian, peristiwa Damsyik merupakan peristiwa di mana Paulus menerima pernyataan tentang Yesus Kristus dan menerima perutusan untuk mewartakan Dia kepada bangsa-bangsa non-Yahudi (bdk. Kis 9: 15; 22:14-15; 26:12-18). Kepada jemaat Filipi, Paulus menyatakan bahwa pengalaman Damsyik mengubah orientasi hidupnya. Ia tidak lagi bermegah pada hal-hal lahiriah sebab pengenalannya akan Kristus itu lebih mulia dari semuanya. Apa yang sebelumnya ia banggakan justru dianggapnya sebagai kerugian dan sampah (Flp 3:7-8). Dengan demikian, Paulus dengan Kristus itu merupakan pengalaman penge-nalan akan Kristus yang mengubah hidupnya: Paulus mengubah orientasi hidupnya dan ingin menjadi serupa dengan Kristus (Flp 3:1011). Pengalaman Damsyik merupakan kisah mengenai rahmat ilahi yang mengubah seorang Saulus yang semula menjadi penganiaya jamaat menjadi seorang Paulus yang gigih mengikuti dan mewartakan Kristus.

Selain itu, transformasi hidup Paulus juga dibantu oleh kehadiran dan peran beberapa sahabat yang menerima dan menemaninya dalam perjalanan hidupnya, khususnya Barnabas. Ketika Paulus tiba di Yerusalem dan para rasul tidak mau menerimanya, Barnabas menerima dia (Kis 9:27). Demikian juga, Barnabaslah yang menjemput Paulus dari Tarsus untuk diajak mewartakan Injil ke Antiokhia (Kis 11:25). Mungkin, inilah peristiwa yang paling menentukan dalam hidup Paulus sebagai manusia biasa karena dalam pertistiwa ini kepercayaan dirinya yang hancur dipulihkan. Paulus yang dianggap pengkhianat oleh orang-orang Yahudi dan tidak dipercaya oleh para murid di Yerusalem, dimasukkan ke dalam lingkungan para nabi dan pengajar di Antiokhia oleh Barnabas (Kis 13:1).

\section{St. Agustinus (354-430)}

Agustinus dilahirkan dan dididik oleh seorang ibu yang iman kekatoliknya sangat mendalam (Monika) dan seorang ayah yang semula kafir tetapi kemudian juga menjadi katolik (Patrisius). ${ }^{3}$ Sejak kanak-kanak, ia sudah tampak sangat cerdas dan cemerlang. Namun, pada usia 15 tahun, orang tuanya tidak mempunyai beaya untuk menye-kolahkanya sehingga ia menjadi penganggur. Akibatnya, ia jatuh pada banyak perilaku buruk baik secara hukum maupun moral. Berkat bantuan Romanianus, Agustinus dapat melanjutkan pendidikannya pada usia 17 tahun di Kartago. Sayang perilaku buruknya tidak berhenti. Ia hidup dengan seorang wanita tanpa ikatan perkawinan selama 15 tahun dan dikaruniai seorang anak (Adeodatus). Monika senantiasa berdoa dan berharap agar Agustinus segera bertobat dan menjadi Kristen. Akan tetapi, hal itu baru terwujud pada tahun 387, yaitu ketika Agustinus bertobat dan dibaptis oleh Ambrosius.

Pada tahun 373, Agustinus membaca buku Hortensius karangan Cicero. ${ }^{4}$ Buku tersebut menyatakan bahwa kebahagiaan sejati yang menjadi dambaan setiap orang tidak didapatkan dari hal-hal lahiriah tetapi dari hal-hal spiritual yang diberikan oleh filsafat. Hal ini sejalan dengan pandangan dualistis Manikeisme yang salah satunya mengajarkan bahwa di dunia ini, jiwa terperosok dalam tahanan tubuh dan akan terangkat kembali ke dunia asalinya hanya 
dengan perantaraan gnosis. Pada saat itu, Agustinus yang sedang mengalami konflik batin antara hawa nafsunya yang tinggi dengan perasaan bersalah dan menyesal atas dosa-dosanya menjadi sangat tertarik dengan cara mati raga yang dihayati kelompok Manikheis sebagai sarana untuk melepaskan dan membersihkan diri dari dosa. Ia pun kemudian menjadi anggota Menikheis antara tahun 373-383.

Pada tahun 384, ia mendapatkan kedudukan akademis dan politis yang menonjol di dunia Latin, yaitu sebagai dosen di Milano. Di sana, Agustinus berjumpa dengan Ambrosius, seorang uskup dan ahli retorika seperti dirinya tetapi jauh lebih berpengalaman. Ia juga berjumpa dengan Nebridius yang berhasil mengguncang kepercayaannya akan astrologi (horoskop). Maka, Agustinus mulai meninggalkan Manikheisme dan beralih pada Neoplatonisme kendati hanya sebentar. Suatu saat, ia mendengar suara seorang gadis kecil yang memberi pesan agar ia "mengambil dan membaca" (tole et lege) Alkitab. Maka, ia pun mulai tertarik mendalami Alkitab dan sangat terbantu oleh kotbah dan cara-cara Ambrosius menerangkan Kitab Suci. Ia menjadikan Ambrosius sebagai guru dan bapa rohaninya yang mampu memberikan pengertian menyeluruh tentang iman kristiani.

Pada tahun 386, setelah membaca riwayat hidup St. Antonius dari Padang Pasir yang sangat memukaunya, Agustinus mengalami krisis pribadi yang mendalam. Ia kemudian menyepi di sebuah rumah di Cassiciacum. Di sanalah, ia memutuskan untuk menjadi seorang Kristen. Ia meninggalkan kariernya dalam retorika, melepaskan jabatannya sebagai dosen di Milano, dan ingin mengabdikan diri sepenuhnya kepada Allah. Akhirnya, ia dibaptis oleh Ambrosius pada tanggal 24 April 387. Setelah dibaptis, ia mengalami kesedihan mendalam karena kematian Monika dan Adeodatus. Pengala-man ditinggalkan oleh orang-orang yang dicintainya itu membuat Agustinus memutuskan untuk kembali ke Afrika dan hidup secara kontemplatif. Pada tahun 391, ia pergi ke Hippo untuk mencari tanah guna membangun biara. Akan tetapi, ia justru didesak oleh umat di sana agar bersedia ditahbiskan menjadi imam. Maka, pada tahun itu juga, ia ditahbiskan sebagai imam oleh Uskup Valerius dan ketika Valerius meninggal dunia pada tahun 395, ia ditunjuk menggantikannya sebagai Uskup Hippo. Ia menjadi gembala yang murah hati, pengkotbah yang ulung, dan pembela kaum miskin. Ia juga gigih membela ortodoksi ajaran iman Gereja berbadapan dengan para bidaah.

\section{St. Ignatius Loyola (1491-1556)}

Ignatius lahir dari keluarga bangsawan sebagai anak bungsu dari 13 bersaudara. Dalam lingkungan hidupnya, ia tumbuh sebagai orang yang ambisius dan suka latihan senjata. Ia pernah menjadi pemimpin gang yang brutal dan terlibat berbagai affair dengan beberapa wanita. Pada tahun 1521, ia terlibat dalam pertempuran melawan Perancis di Benteng Pamplona. Dalam pertempuran tersebut, kakinya terluka parah sehingga ia harus menjalani masa penyembuhan yang cukup lama. Ia hanya bisa berbaring di tempat tidur, ditemani beberapa buku. Sebenarnya, ia menghendaki untuk membaca novelnovel ksatria tetapi yang ada hanya buku Vida di Christo (Riwayat Hidup Kristus) dan Flos Sanctorum (Bunga Rampai Para Kudus). ${ }^{5}$ Melalui kedua buku ini, ia sangat terkesan dengan cara hidup santo-santa, terutama laku tapa mereka. Ia mulai tertarik dan bertekad untuk meninggalkan hal-hal duniawi dan melakukan mati raga untuk mendapatkan kebahagiaan sejati.

Setelah sembuh, Ignatius mulai melaksanakan tekadnya. Pada tahun 1522, ia pergi ke Montserrat dengan naik keledainya. ${ }^{6}$ Di sana, ia membersihkan jiwanya dengan membuat pengakuan umum untuk seluruh hidupnya di hadapan seorang rahib Perancis. Pada malam menjelang Perayaan Kabar Sukacita (25 Maret), ia menanggalkan senjatanya dan meletakkannya di atas altar. Ia memberikan pakaian mewahnya kepada seorang gelandangan, kemudian memakai jubah peziarah dari goni dan melakukan doa-tugur semalaman di kaki Maria: kadang berdiri, kadang berlutut. Pagi harinya, secara diam-diam, ia meninggalkan Montserrat menuju Manresa. 
Di Manresa, Ignatius hidup layaknya seorang peziarah miskin. ${ }^{7}$ Ia terus mengembangkan devosinya dan mencurahkan tenaganya untuk melakukan amal kasih kepada orang miskin dan orang sakit. Di sana, ia mengalami proses evolusi batin yang dapat dibagi menjadi 3 masa. $^{8}$ Masa pertama adalah masa tenang, di mana ia selalu berada dalam "keadaan yang amat damai dibarengi rasa gembira, namun tanpa pengetahuan jelas mengenai hal-hal batin rohaninya". Selama masa ini, ia hidup dari derma, tidak makan daging dan minum anggur, berdoa 7 jam setiap hari, dan selalu memusatkan hidupnya pada hal-hal rohani. Masa kedua adalah ketika ia harus mengalami perjuangan batin melawan keraguan dan skrupel dalam dirinya. Ia selalu ragu dan merasa bersalah: janganjangan ia telah melalaikan suatu dosa atau tidak cukup baik menjelaskan dosa-dosa yang dilakukannya. Dalam situasi seperti itu, ia tetap melakukan laku tapa dan olah rohani tanpa henti sampai akhirnya mengalami pembebasan dari skrupelnya secara tiba-tiba. Apa yang tidak dapat dicapai oleh segala daya upaya manusiawinya dicapai oleh rahmat ilahi. Dalam masa ketiga, ia menerima pencerahan ilahi yang mengagumkan kemudian menyusun Latihan Rohani. Beberapa kali ia mendapat penampakan dan pencerahan budi dalam doa-doanya.

Di antara banyak pengalaman rohaninya, Ignatius mempunyai satu pengalaman yang secara khusus membekas dalam jiwanya dan sangat mengubah seluruh masa depannya, yaitu "pencerahan hebat" (eximina ilustracón) yang dialaminya. ${ }^{9}$ Pada suatu hari, ia berziarah ke Gereja St. Paulus di Manresa. Di tengah jalan, ia terdorong untuk duduk sebentar menghadap Sungai Cardoner. Ketika ia duduk di sana, mata pikirannya terbuka. Ia tidak mendapat penampakan tetapi mendapat pencerahan sehingga dapat mengetahui dan memahami banyak hal. Di sinilah Tuhan menunjukkan kepadanya hal-hal yang kemudian ia perintahkan di dalam Serikat Yesus. Arti pentingnya pencerahan di Sungai Cardoner ini adalah bahwa Ignatius kemudian mengubah arah hidupnya. Ia tidak lagi menjadi peziarah yang hidup menyendiri, yang dalam doa dan silihnya mencoba mengikuti teladan santo-santa, tetapi membaktikan diri untuk bekerja demi kebaikan sesama dan mencari rekan kerja yang akan bergabung dengannya untuk membentuk badan kerasulan.

Untuk mewujudkan cita-citanya tersebut, Ignatius melakukan serangkaian studi bahasa, filsafat, dan teologi di Barcelona (1524-1526), kemudian di Alcaca dan Salamanca (1526-1527), akhirnya di Paris (1527-1535). Di Paris, ia berkenalan dengan Petrus Faber dan Fransiskus Xaverius. Mereka berencana untuk pergi dan tinggal di Venesia sebagai pelayan rumah sakit. Ignatius tiba di Venesia pada awal tahun 1536 dan temantemanya menyusul pada awal tahun 1537. Pada tanggal 24 Juni 1537, mereka ditahbiskan sebagai imam dan pada bulan November tahun yang sama, mereka menuju kota Roma dan menetap di sana. Di Roma, mereka memutuskan untuk saling mengikatkan diri dalam suatu ordo religius yang diberi nama Serikat Jesus. Pada tanggal 27 September 1540, Paus Paulus III mengeluarkan bulla Regimini Militantis Ecclesiae untuk mengukuhkan berdirinya ordo Serikat Yesus.

\section{St. Teresa Avila atau Teresa dari Yesus (1515-1582)}

Teresa Avila lahir dari keluarga katolik yang saleh di Spanyol. Pada masa kecil, ia sangat gemar membaca kisah santo-santa bahkan sampai ingin segera mati dan naik ke surga supaya dapat menikmati keindahan yang ia baca. Pada masa remaja, Teresa membaca buku Letter of St. Jerome, pemberian Don Pedro, pamannya yang menjadi imam. Buku tersebut menyentuh dan mendorongnya untuk masuk biara karena ia melihat bahwa kehidupan religius merupa-kan cara yang paling tepat untuk memaknai hidupnya. ${ }^{10}$ Maka, pada tanggal 2 November 1535, Teresa masuk biara Karmel Inkarnasi di Avila dan dua tahun kemudian mengucapkan kaul pertamanya.

Setahun setelah menjadi rubiah Karmel, ia sakit keras dan pernah hampir mati karena salah obat. Pada saat sakit 
tersebut, ia membaca buku karangan Francisco de Osuma, Third Spiritual Alphabet, yang juga diberikan oleh Don Pedro. Buku ini memperkenalkanya pada doa batin yang kemudian dipraktikkannya. Ia juga menda-patkan penghiburan dan kekuatan dari buku karangan St. Gregorius, Moralia, yang merupakan komentar atas Kitab Ayub. Buku ini membuatnya dapat belajar dari Ayub untuk tidak hanya menerima hal-hal baik dari Allah tetapi juga menerima hal-hal buruk dari-Nya (bdk. Ayb 2:10) dengan sabar dan bahagia dalam doa.

Setelah sambuh dari sakitnya, Teresa mengalami kebingungan, tidak tahu arah, dan tidak tahu harus berbuat apa selama 14 tahun. Ia menyebut masa ini sebagai masa suam-suam kuku. Syukur, ia menemukan buku tulisan Agustinus, Confessiones. Melalui buku tersebut, Teresa merasakan bahwa dirinya menerima rahmat ilahi seperti yang diterima Agustinus sehingga ia mulai membaktikan dirinya untuk tinggal dalam Yesus Kristus dan mencintai-Nya. Dalam hidup baru ini, ia mulai dibanjiri suka cita dan pengalaman rohani. Namun, keragu-raguan segera menyerang dirinya: jangan-jangan hiburan rohaninya tidak datang dari Allah tetapi dari iblis. Maka, atas inspirasi dari buku tulisan Bernardino de Laredo, Climbing the Zion Mountain (Mendaki Gunung Zion), Teresa menuliskan pengalaman-pengalaman spiritualnya dalam "catatan tentang kehidupan dan dosaku". Ia juga mengadakan bimbingan dengan Don Francisco de Salcedo dan Maestro Daza yang kemudian mempertemukannya dengan Diego de Cetina, seorang Yesuit yang ahli dalam doa batin. Diego de Catina meyakinkan bahwa doa dan penghiburan rohani Teresa berasal dari Allah sehingga ia sungguh mendapatkan peneguhan.

\section{Edith Stein (1891-1942)}

Edith Stein lahir dari keluarga Yahudi di Breslau, Polandia. Sejak berusia 21 bulan, ia sudah harus berhadapan dengan situasi pahit karena ayahnya, Siegfried Stein, meninggal dunia. ${ }^{11}$ Seluruh tanggung jawab keluarga kemudian diambil alih ibunya, Agusta Stein. Situasi tersebut membuat Edith Stein berkembang dalam watak yang tidak mudah menyerah terhadap kesulitan-kesulitan hidup yang dihadapinya. Ia memiliki pemikiran yang tajam, cemerlang dan mampu mengingat banyak hal dengan baik. Pada usia 7 tahun, Edith Stein mulai sekolah di Victoria School. Ia tumbuh sebagai anak yang cerdas dan mampu mengungkapkan pemikirannya seperti layaknya orang dewasa. Oleh karena itu, di satu sisi ia merasa bahagia karena dapat belajar tetapi di sisi lain merasa tidak puas dengan pelajaranpelajaran di kelas yang tidak sesuai dengan tingkat pemikirannya. Ia pun menjadi suka menyendiri, mudah marah, murung, dan tidak bahagia. Pada usia 13 tahun, ia mengalami depresi sampai tidak mau lagi bersekolah. Oleh ibunya, ia kemudian dikirim kepada kakaknya, Else, di Hamburg untuk mendapatkan bantuan dalam mengolah dan mengatasi depresinya.

Antara tahun 1908-1911, Edith Stein meneruskan SMA di Victoria School. Selama masa itu, ia mengalami krisis iman: tidak percaya lagi akan eksistensi Allah sebagai Pribadi. Ia mengakui bahwa selama masa tersebut, ia telah kehilangan kemampuan untuk berdoa dan menjadi seorang ateis. ${ }^{12}$ Setamat SMA, ia belajar literatur Jerman dan sejarah di Universitas Breslau (1912-1913) kemudian meneruskan dalam bidang filsafat dan psikologi di Universitas Gottingen (1914-1916). Di Gottingen, ia berjumpa dengan beberapa filsuf yang berpengetahuan luas dan beriman mendalam, antara lain: Edmund Husrel, Adolf Reinach, Max Sheler, Theodor Conrad, dan Moritz Geiger. Mereka berhasil membawa Edith Stein masuk dalam suasana religius dan filsafat yang mampu meruntuhkan pandangan ateismenya sehingga ia mulai terbuka pada Tuhan.

Setelah meraih gelar Doktor dari Gottingen pada tahun 1916, Edith Stein menjadi asisten Prof. Edmund Husrel di Universitas Freirburg. Setahun kemudian, Adolf Reinach, dosennya di Gottingen meninggal dunia. Ia kagum dengan $\mathrm{Ny}$. Reinach yang sangat tabah dan pasrah menerima kematian suaminya. Bagi Edith Stein, sikap Ny. Reinach tersebut mencerminkan penghayatan iman katolik yang 
mendalam, yaitu dengan tabah mengambil bagian dalam salib Kristus. Maka, nya dengan Ny. Reinach ini semakin membuka dirinya untuk kembali beriman kepada Tuhan. Pada tahun 1918, ia meninggalkan profesinya sebagai asisten Husrel dan kembali ke Breslau. Ia mengalami dorongan kuat untuk menjadi katolik tetapi juga mengalami pergulatan hebat karena keluarganya sangat keberatan. Namun, dorongan itu semakin kuat ketika pada tahun 1921, ia membaca otobiografi St. Teresa Avila. Maka, setelah melalui pertimbangan yang matang, ia memutuskan untuk dibaptis pada tanggal 1 Januari 1922 di Gereja St. Martinus Bergzabern. Sebelas tahun kemudian, tepatnya tanggal 14 Oktober 1933, ia masuk biara Karmelit di Köln, Jerman dan menggunakan nama Sr. Theresia Benedicta dari Salib, OCD.

Pada tanggal 9 November 1938, ketika kebencian Nazi terhadap orang-orang Yahudi mulai diwujudkan dalam bentuk penahanan dan penganiayaan, nyawa Edith Stein terancam. Maka, ia dipindahkan ke Biara Echt di Belanda. Namun, pada bulan Juli 1942, Nazi datang ke biara dan menangkap Edith Stein serta Rosa, kakaknya yang berkerja di situ. Mereka dibawa ke kamp konsentrasi di Amersfoort, Westerbork, dan akhirnya ke Auschwitz. ${ }^{13}$ Pada tanggal 9 Agustus 1942, Edith Stein dibakar bersama dengan orang-orang Yahudi lainnya sebagai korban kekejaman Nazi.

\section{Doroty Day (1897-1980)}

Dorothy Day lahir di Brooklyn, Amerika Serikat dari sebuah keluarga miskin yang sering berpindah-pindah rumah. Sepanjang hidupnya, Amerika Serikat diwarnai oleh suasana perang yang menimbulkan penindasan, ketidakadilan, dan penderitaan. Situasi tersebut mendorong Dorothy Day untuk megembangkan minatnya pada bidang jurnalistik menjadi aktivitas sosial berhaluan kiri (Marxis) untuk memperjuangkan keadilan dan membela kaum tertindas. Sebelum dibaptis, ia menganut gaya hidup bebas dan berpikiran sangat radikal. ${ }^{14}$ Beberapa kali ia menjalin hubungan dengan laki-laki, entah dalam ikatan perkawinan entah tidak. Ia juga pernah hamil dan melakukan aborsi. Laki- laki terakhir yang hidup bersamanya tanpa ikatan perkawinan adalah Forster Batterham, seorang ateis yang anarkis. Hubungan mereka menghasilkan seorang anak yang lahir pada tahun 1926. Namun, karena Batterham menolak pernikahan, Dorothy Day kemudian meninggalkannya dan mengasuh anaknya seorang diri. Ia mendapat bantuan dari Sr. Aloysia yang membawanya masuk dalam komunitas Gereja setempat. Di situlah, Dorothy Day mengalami penerimaan dan kasih persaudaraan yang luar biasa. Maka, pada tanggal 28 Desember 1927, ia memutuskan untuk dibaptis bersama dengan anaknya, Tamar Teresa.

Pada tahun 1930, Dorothy Day merintis koran The Catholic Worker (CW) untuk menyuarakan perjuangannya menegakkan keadilan. Tiga tahun kemudian, yaitu pada tahun 1933, bersama dengan Peter Maurin, seorang Fransiskan dari Perancis, ia mendirikan Catholic Worker Movement untuk membela kaum miskin dan tertindas melalui aksi non-violance. Dalam perkembangannya, gerakan ini juga membuat House of Hospitality di daerah kumuh di New York untuk menampung, merawat, dan mendam-pingi para gelandangan, pengemis, orang-orang jompo, pemabuk dan pelacur. Dengan setia, Dorothy Day melayani mereka dan memperjuangkan nasib mereka, kendati harus berhadapan dengan berbagai rintangan dan kesulitan. Melalui mereka yang menderita dan disingkirkan oleh masyarakat itulah, Dorothy Day menemukan Allah dan mengabdi kepada-Nya. Pada tanggal 2 Desember 1980, Dorothy Day meninggal dunia dan dimakamkan di New York. Pada tahun 2000, Paus Yohanes Paulus II memberinya gelar "Pelayan Tuhan".

\section{Thomas Merton (1915-1968)}

Thomas Merton dilahirkan dalam keluarga seniman di Prades, Perancis. Pada usia 6 tahun, ia sudah ditinggal mati ibunya. Akibatnya, ia harus mengikuti ayahnya berpindah dari satu tempat ke tempat yang lain. Pada tahun 1931, ketika ia berusia 16 tahun, ayahnya juga meninggal dunia. Kematian ayahnya ini menjadi awal dari kekacauan hidup 
Thomas Merton. Ia masuk dalam kelompok anak-anak yang suka mabuk-mabukan di bar, membolos kuliah dan suka mengganggu asrama universitas. Ia juga menjadi lakilaki hidung belang yang sering memanfaatkan wanita sebagai peneguh harga diri tanpa hubungan dan perasaan cinta sejati. ${ }^{15}$ Pada akhir tahun 1934, Merton terpengaruh pada pemikiran-pemikiran Karl Marx yang dibacanya dan kemudian menjadi anggota Partai Komunis di Amerika Serikat. $^{16}$

Pada suatu ketika, ia berjumpa dengan seorang rahib Hindu yang menyarankannya untuk membaca tulisan St. Agustinus. Ia sangat terkesan dengan kisah hidup Agustinus dan merasa tersentuh untuk mengalaminya sendiri. "Thomas semakin yakin bahwa segala sesuatu di dunia ini tidak memadai lagi. Kebahagiaan yang lestari bagi jiwa manusia tidak dapat diperoleh karena kekuatan manusia sendiri. Kebahagiaan itu hanya dapat diperoleh dari Allah. Berbagai kesan dan pengalaman membuat Thomas sadar bahwa dia harus melangkah ke jalan iman." ${ }^{17}$ Maka, pada tahun 1938, ia memutuskan untuk dibaptis dan kemudian mendalami hidup rohani katolik.

Dua tahun kemudian, ia memutuskan untuk masuk biara Fransiskan karena tertarik pada cara hidup para Fransiskan yang menghayati kemiskinan dengan gembira dan bebas dari paksaan dan rutinitas. Akan tetapi, ketika ia menceritakan masa lalunya dengan terbuka dan jujur, ia justru ditolak untuk masuk biara Fransiskan. Hal ini tidak mematahkan semangatnya. Ia malah ingin hidup membiara yang lebih keras sebagai rahib. Ia berhenti merokok, melakukan ibadat harian, dan mengikuti latihan rohani di Biara Getsemani, sampai akhirnya diterima menjadi anggota Trapist di biara tersebut pada tanggal 10 Desember 1941. Pada tahun 1947, ia mengikrarkan kaul kekalnya dan dua tahun kemudian ditahbiskan sebagai imam.

Dalam biara, Thomas Merton mengikuti ritme hidup pokok berupa Ofisi 5 kali sehari dan kerja tangan 5 jam sehari. Ia juga mengalami pergulatan berkaitan dengan cara hidup yang dipilihnya. Di satu sisi ia bahagia dengan menjadi rahib dan tinggal di biara tetapi di sisi lain ia juga ingin mengambil bagian dalam menghadapi permasalahan-permasalahan dunia luar. ${ }^{18}$ Syukur, ia dapat memperdamaikan pergulatannya tersebut dengan menulis banyak buku untuk menang-gapi masalah-masalah konkret dan aktual di masyarakat dalam terang pengalaman-pengalaman iman dan rohaninya yang ia geluti di biara. Ia juga mendapat dorongan dari Abas di biaranya untuk menggali kekayaan rohani dari para mistikus Islam, Budha, Hindu, dan Zen sehingga tulisan-tulisannya semakin kaya dan sungguh merupakan wujud kepeduliannya terhadap dunia.

\section{FAKTOR-FAKTOR TRANSFORMATIF DALAM HIDUP}

Bertolak dari kisah hidup para tokoh Gereja yang telah dipaparkan di atas, dapat ditarik beberapa simpul pengalaman yang kiranya merupakan faktor penyebab terjadinya transformasi dalam hidup seseorang. Beberapa faktor penyebab terjadinya transformasi tersebut antara lain:

\section{Rahmat Tuhan}

Pengalaman transformasi hidup berkat rahmat ilahi yang istimewa dialami oleh St. Paulus dan St. Ignatius Loyola. Paulus mengalami transformasi berkat dan pengenalannya akan Kristus yang menorehkan pengalaman rohani secara mendalam. Pengalaman itu membuat Paulus mengenali Yesus sebagai Dia yang bangkit, di mana sebelumnya ia hanya mengenal Yesus yang mati disalib yang berarti mati secara hina karena dikutuk Allah (Ul 21:23; Gal 3:13). Sebagai seorang Farisi, Paulus percaya akan kebangkitan badan. Maka, ketika berjumpa dengan Yesus yang bangkit, ia mengerti bahwa iman jamaat kristen akan Yesus yang bangkit itu bukanlah iman yang hampa. Lambat laun, ia pun mulai percaya dan beriman pada Yesus. Paulus mengerti bahwa Yesus yang dibencinya sebenarnya Dia yang layak dicintai dan diwartakan ke mana-mana, bahkan harus dibela sampai mengorbankan nyawanya.

Sebagai orang yang telah mengimani Kristus, Paulus tetap mengabdi Allah yang 
sama dengan Allah yang ia abdi sebelumnya. Namun, ia tidak lagi menganggap bahwa Allah yang diabdinya hanya milik orang Yahudi secara eksklusif, tetapi Allah sebagai Bapa Tuhan kita Yesus Kristus (Rm 15:6) yang terbuka kepada semua orang. Ia juga tidak menanggalkan ke-Yahudi-annya, tetapi tidak lagi bermegah atas ke-Yahudiannya itu dan justru mengganggapnya sebagai sampah yang merugikan (Flp 3:48). Ia tidak lagi memutlakkan Taurat untuk mencapai keselamatan (Rm 3:19-20) sebab keselamatan hanya akan terjadi dalam iman dan kesatuan dengan Yesus Kristus (Rm 5$6)$.

Hampir sama dengan Paulus, Ignatius Loyola juga mengalami transformasi hidup berkat nya dengan Tuhan yang memberinya pencerahan. Memang, ia tidak mendapat penampakan tetapi mendapat pencerahan sehingga dapat mengetahui dan memahami banyak hal. Tuhan mencerahkan hati dan budinya sehingga cintanya kepada Allah semakin berkobar. Cinta yang semula dihayati dengan hidup menyendiri dalam doa dan peziarahan diubah arahnya menjadi cinta yang dibaktikan demi kebaikan sesama. Cinta yang semula melulu vertikal antara Ignatius dan Allah, diubah menjadi vertikal dan horizontal yaitu antara Ignatius, Allah, dan sesama.

\section{Sikap dan Tindakan Tobat}

St. Ignatius Loyola dan juga tokoh-tokoh yang lain sungguh berhasil melakukan transformasi hidup berkat sikap dan tindakan tobat yang dibangunnya. Sebab, meskipun inisiatif untuk mengawali proses pertobatan itu berasal dari Allah, manusia tetap mempunyai peran dalam proses tersebut. ${ }^{19}$ Sikap dan tindakan tobat ini sangat tampak dalam diri Ignatius Loyola, yaitu ketika di Montserrat ia membersihkan jiwanya dengan membuat pengakuan umum untuk seluruh hidupnya. Ia mempersiapkan pengakuannya tersebut dengan pemeriksanaan batin secara jujur dan rendah hati. Pemeriksaan batin akan melahirkan penyesalan mendalam, yaitu kesadaran bahwa dosa telah menyebabkan penghinaan terhadap Allah. Maka, ia pun menemukan orientasi hidupnya yang benar yaitu untuk mengasihi Allah dengan cara memuji, menghormati dan mengabdi-Nya (LR no. 23). Ia pun mengubah hidupnya, yaitu hidup sesuai dengan tujuan ia diciptakan.

Setelah mengalami eximina ilustracón di Manresa, Ignatius menuliskan pentingnya pemeriksaan batin untuk mengubah hidup, terutama untuk menghilangkan dosa atau kekurangan khusus dalam Latihan Rohani (LR no.24-43). Ia menegaskan bahwa, "Sebagaimana gerak jalan, jarak dekat atau jarak jauh, dan lari-lari dapat disebut latihan jasmani, demikian pula dinamakan latihan rohani setiap cara mempersiapkan jiwa dan menyediakan hati untuk melepaskan diri dari segala tidak rasa lekat tidak teratur, dan selepasnya dari itu menemukan kehendak Tuhan dalam hidup nyata guna keselamatan jiwa kita". Maka, tujuan latihan rohani adalah untuk, "menakhlukkan diri dan mengatur hidup begitu rupa hingga tak ada keputusan di ambil di bawah pengaruh rasa lekat tak teratur mana pun juga" (LR no.21). Dengan demikian, latihan rohani merupakan salah satu sarana untuk melakukan transformasi diri demi hidup yang selaras dengan kehendak Tuhan.

\section{Olah Rohani}

Pengalaman dengan Allah atau disentuh oleh Allah secara personal tidak selalu otomatis membuat transformasi dalam diri seseorang. Pengalaman itu harus diolah, direnungkan, dan direfleksikan supaya dapat ditemukan maknanya yang paling dalam. Setelah berjumpa dengan Kristus, Paulus "mengasingkan" diri ke tanah Arab selama kurang lebih dua tahun (34-36) untuk merenungkan makna terdalam dari penga-laman rohaninya itu. Pemaknaan tersebut kiranya juga semakin diperdalam seiring dengan refleksi yang dibuatnya dalam perjalanan waktu sebagaimana yang disha-ringkannya kepada jemaat Galatia (21 tahun setelah peristiwa Damsyik) dan Filipi (27 tahun setelah peristiwa Damsyik). Demikian pula, pengalaman St. Ignatius dalam retret yang ia beri nama latihan rohani. Atas dasar pengalaman hidup Ignatius, retret atau latihan rohani ternyata mempunyai dampak luar biasa bagi transformasi hidupnya. 
St. Agustinus juga sangat terbantu untuk mengalami transformasi hidup melalui refleksi yang dibuat dan ditulisnya dalam Confessiones (ditulis sekitar tahun 397/398). Dalam refleksinya tersebut, ia dengan jujur menyadari masa lalunya yang buruk sambil terus membuka diri pada bimbingan rahmat Allah yang membantunya untuk bertobat. Maka, keterbukaan dan kejujuran untuk menerima masa lalu dalam refleksi dan doa, kiranya juga merupakan sarana bagi seseorang untuk mengalami pengubahan hidup. Tokoh-tokoh lain seperti Ignatius Loyola dan Thomas Merton kiranya juga semakin berhasil dalam membuat pengubahan hidup berkat renungan, doa-doa dan devosi yang mereka jalani dengan tekun. Itu semua menunjukkan bahwa keterbukaan pada rahmat dan karya Allah mempunyai daya ubah atas hidup manusia yang terbatas dalam banyak hal. Misalnya, ketika Ignatius tidak berdaya mengatasi keraguan dan skrupelnya tetapi tetap tekun dalam devosi, doa dan matiraga, Allah berkarya secara tak terduga. Tiba-tiba, Allah membebaskannya dari keragu-raguan dan sikap skrupelnya.

Selain itu, pengalaman pertobatan Agustinus kiranya juga tidak terlepas dari doa-doa Monika, ibunya. Ketika Agustinus masih kafir, Monika selalu tekun berdoa agar anaknya bertobat sampai akhirnya doadoanya terkabul dengan dibaptisnya Agustinus. Dengan demikian, doa yang dilakukan seseorang untuk memohon rahmat Tuhan agar Ia berkenan mengubah hidup orang lain, kiranya juga merupakan kekuatan transformatif yang tidak dapat diabaikan begitu saja.

\section{Kehadiran dan dengan Orang Lain}

dengan orang lain, entah dalam rangka bimbingan, sharing, diterima, dibantu atau sekedar menyaksikan apa yang dialami/ dibuat orang lain juga mempunyai daya transformatif. Perjalanan rohani itu bukan hanya masalah pribadi, melainkan selalu perjalanan bersama orang lain. ${ }^{20}$ Sebab, kehadiran orang lain seringkali sangat membantu seseorang untuk mengolah, merefleksikan, dan memaknai pengalamanpengalaman hidupnya secara lebih jernih. Teresa Avila sungguh diteguhkan oleh para pembimbing rohaninya: Don Fransisco de Salcedo, Maestro Daza, dan Diego de Catina sehingga ia semakin berkembang dalam kesalehan dan kesucian. Agustinus mening-galkan Manikheisme berkat peran Nebridius yang menghancurkan pandangan Menikheis yang diyakininya. Ia juga semakin terbantu untuk memahami Kitab Suci dan iman kristiani sehingga bertobat dan dibaptis berkat nya dengan Ambrosius, baik melalui kotbah, pengajaran, maupun bimbingan rohani. Demikian juga Edith Stein. Ia mengalami transformasi hidup dari seorang ateis menjadi seorang yang mengimani Tuhan berkat nya dengan para dosennya yang berwawasan sangat luas sekaligus beriman mendalam di Universitas Gottingen. Kesaksian iman yang ia temukan dalam diri Ny. Reinach juga membuka mata hatinya untuk menghayati iman yang sama, yaitu dengan dibaptis dan menjadi katolik.

Dalam diri Paulus dan Dorothy Day, kehadiran orang lain yang dengan terbuka memahami dan menerima dirinya apa adanya, membuat mereka yang terpuruk dan tidak berdaya kembali merasa dihargai sehingga dapat bangkit dan berkembang menjadi lebih baik. Kehadiran Barnabas yang mau menerima Paulus ketika para murid yang lain menolaknya sungguh merupakan hal yang sangat berarti bagi Paulus. Demikian juga ketika Barnabas menjemputnya di Tarsus untuk diajak mewartakan Injil di Antiokhia. Boleh dikatakan peran Barnabas dalam hidup Paulus sangat menentukan perkembangan hidupnya. Tanpa Barnabas, mungkin Paulus akan tetap menjadi orang yang ditolak dalam lingkaran para murid. Tanpa Barnabas pula, mungkin Paulus akan tetap tinggal di Tarsus dan tidak dikenal sebagai Rasul Agung yang mewartakan Injil di berbagai tempat dan memberikan warisan iman dan moral yang sungguh kaya bagi Gereja.

Sementara itu, Dorothy Day merasa diterima dalam kasih persaudaraan oleh $\mathrm{Sr}$. Aloysia dan komunitas Gereja setempat meskipun mereka tahu bahwa hidupnya kacau. Hal ini memberanikan dia untuk dengan mantap meninggalkan masa lalunya dan membangun hidup baru dengan memeluk iman katolik. Sebagai orang 
katolik, aktivitas sosial yang sebelumnya dijalankan hanya sebagai pekerja sosial yang berhaluan kiri (Marxis), diubah menjadi solidaritas yang bersumber pada pengurbanan Yesus di salib demi keselamatan manusia. Ia membela, mencintai, dan melayani orang miskin dan menderita, bukan sekedar karena rasa belas kasih manusiawi, tetapi karena digerakkan oleh kasih Allah yang dicurahkan kepadanya dan kepada sesamanya. Ia keluar dari gerakan Marxisme dan bergabung dengan gerakan Fellowship of Reconciliation yang mempunyai komitmen untuk berjuang demi terwujudnya keadilan dan perdamaian. Akhirnya, bersama dengan teman-temannya, ia mendirikan dan mengelola The Catholic Worker, Catholic Worker Movement, dan House of Hospitality sebagai jalan untuk mengabdi Allah dan sarana melayani sesama.

Dilihat dari perspektif Teori Perkembangan Moral (Lawrence Kohlberg) dan Teori Perkembangan Iman (James W. Fowler), peran orang lain dalam perkembangan hidup seseorang memang cukup penting. ${ }^{21}$ Kohlberg menyatakan bahwa salah satu faktor utama yang mempengaruhi perkembangan moral seseorang adalah lingkungan sosial, yaitu: orang lain yang hidup bersama dalam jangka waktu tertentu atau mempunyai intensitas yang teratur. Ia menegaskan bahwa untuk dapat berkembang dengan baik, seseorang membutuhkan dukungan dari lingkungan sosialnya berupa pemberian motivasi untuk mengembangkan struktur-struktur kognitif dalam mencari pemecahan atas masalahmasalah yang dihadapi. Selain itu, ia juga memerlukan lingkungan sosial yang memungkinkannya untuk berjumpa dengan sebanyak mungkin pengalaman sosial sehingga ia terdorong untuk berpikir guna memecahkan persoalan sosial yang dihadapinya. Sementara itu, Fowler menekankan pentingnya dukungan dari komunitas iman (orang lain yang seiman) agar seseorang dapat mengeks-presikan iman yang ada dalam dirinya sehingga ia menjadi lebih terbuka untuk mengembangkan diri dan imannya.

\section{Bacaan Rohani}

Hampir semua kisah hidup tokoh-tokoh Gereja di atas menunjukkan bahwa bukubuku yang mereka baca mempunyai peran yang sangat penting dalam memberikan inspirasi untuk melakukan transformasi atau pengubahan hidup. Agustinus menyadari bahwa kebahagiaan sejati tidak diberikan oleh hal-hal lahiriah tetapi oleh hal-hal spiritual kemudian mulai mengubah orientasi hidupnya untuk mencari dan menghidupi hal-hal spiritual setelah membaca buku Hortensius karangan Cicero, kendati ia baru sungguh-sungguh menemukan pegangan hidup setelah tekun membaca dan merenung-kan Alkitab. Ignatius Loyola mulai tertarik dan bertekad meninggalkan hal-hal duniawi dan melakukan mati raga untuk mendapat-kan kebahagiaan sejati seperti yang dihayati para santo-santa berkat buku Vida di Christo dan Flos Sanctorum yang dibacanya semasa sakit. Demikian pula, Teresa Avila yang sejak kecil memang sudah hidup dengan baik, semakin berkembang menjadi lebih baik, suci, dan dekat bahkan bersatu dengan Tuhan lewat buku-buku yang dibacanya: kisah santo-santa, Letter of St. Jerome, Third Spiritual Alphabet, Moralia, Confessiones, dan Climbing the Zion Mountain.

Edith Stein yang memiliki dorongan kuat untuk menjadi katolik tetapi mengalami pergulatan hebat karena keluarganya yang beragama Yahudi menentangnya, menjadi semakin mantap dan akhirnya memutuskan untuk dibaptis setelah membaca dan merenungkan otobiografi St. Teresa Avila. Bahkan buku tersebut menggerakannya untuk mengikuti jejak Teresa dengan menjadi seorang suster Karmelit. Thomas Merton yang mempunyai masa lalu yang kelam (suka mabuk, membuat kekacuan dan memper-mainkan wanita) berani meninggalkan itu semua dan melangkah di jalan iman setelah membaca tulisan-tulisan St. Agustinus. Ia sangat tersentuh oleh kisah hidup Agustinus dan tergerak untuk mengalami sendiri apa yang dibacanya itu sehingga memutuskan untuk dibaptis dan kemudian menjadi seorang rahib. 
Fakta-fakta di atas menunjukkan bahwa bacaan rohani merupakan salah satu faktor penting yang menginspirasi seseorang untuk mengubah dan memperbaiki hidupnya. Sebab, dengan membaca buku-buku rohani, orang menjadi sadar bahwa dirinya sedang melakukan perjalanan rohani dalam bimbingan Allah menuju persatuan denganNya. ${ }^{22}$ Buku-buku rohani memungkinkan pembacanya untuk menangkap karya dan rahmat Allah yang tertulis di dalamnya sehingga ia dapat menimba inspirasi dan belajar untuk menanggapi rahmat Allah yang bekerja dalam dirinya sendiri. Dalam hal ini, buku-buku rohani klasik, ${ }^{23}$ kisah santo-santa dan otobiografi para kudus kiranya merupakan buku bacaan rohani yang sangat besar maknanya. Sebab, melalui buku-buku tersebut pembaca dapat belajar dari pengalaman konkret para kudus, bagaimana mereka melakukan pengubahan hidup dari yang tidak/kurang baik menjadi baik dan terus berjuang untuk menjadi lebih baik lagi. Otobiografi para kudus juga memberikan contoh konkret bagaimana mereka menapak maju dalam perjalanan hidup mereka. ${ }^{24}$

\section{Rekomendasi}

Sebagai orang beriman, tentu kita mengharapkan dan berjuang untuk menjadi pribadi yang sepenuhnya bersandar pada Allah dan akhirnya bersatu dengan Dia. Inilah tahap puncak dari perkembangan iman yang dikemukakan oleh James W. Fowler. Setelah melewati proses perkembangan yang pan-jang dan berliku-liku, mereka telah berhasil melepaskan diri dari egonya (kenosis) dan menyerahkan diri secara total kepada Allah untuk mengabdiNya dan melayani sesama. Mereka telah mengalami kesatuan dengan Allah dan menjadikan Dia sebagai satu-satunya orientasi hidup mereka. Maka, demi keberhasilan transformasi hidup kita, ada baiknya kita belajar dan meneladan mereka dalam beberapa hal berikut ini:

a. Selalu membuka diri dan melatih kepekaan untuk menerima rahmat Tuhan yang secara tiba-tiba dan tidak terduga kadang menyentuh dan menggerakkan kita untuk memilih dan memutuskan sesuatu demi perkembangan hidup kita.

b. Membangun sikap dan tindakan tobat yang sejati. Pertobatan ini harus dipersiapkan dengan pemeriksanaan batin yang jujur dan rendah hati sehingga kita sungguh menyadari dosa-dosa kita. Kemudian, berangkat dari kesadaran akan dosa tersebut, kita membangun pertobatan sejati, yang meliputi: penyelarasan dan niat memperbaiki diri, pengakuan dosa, perbuatan silih, dan kesediaan untuk menerima hukuman dosa.

c. Tekun dan setia melakukan refleksi dan doa, baik dalam kesempatan biasa di tengah aktivitas hidup sehari-hari maupun dalam kesempatan khusus seperti dalam rekoleksi dan retret. Hal ini akan membuat kita semakin peka dalam mengolah dan memaknai pengalaman-pengalaman hidup kita. Pe-ngalaman adalah guru yang baik. Sementara itu, doa merupakan kesempatan yang baik untuk bersyukur atas perkembangan hidup kita sekaligus memohon agar Tuhan membantu usaha-usaha kita dalam bertobat dan mengubah hidup serta memperbaiki diri terus-menerus.

d. Terbuka dan jujur untuk membagikan pengalaman hidup kita kepada orang lain sehingga kita terbantu dalam mengolah dan memaknai pengalamanpengalaman kita tersebut. Maka, keterbukaan untuk berbagi pengalaman tersebut sebaiknya disertai dengan keterbukaan untuk menerima bantuan dari orang lain, baik berupa doa, nasihat, bimbingan, anjuran, larangan, dan lain-lain demi kebaikan kita. Sebaliknya, kalau suatu saat kita dipercaya untuk mendengarkan dan memberi bantuan kepada orang lain, kita juga melakukannya dengan senang hati.

e. Tekun dan setia membaca buku-buku rohani sehingga kita dapat menimba kekayaan rohani di dalamnya serta mendapatkan inspirasi yang menggerakkan kita untuk hidup lebih baik. Buku-buku rohani juga membuka peluang bagi kita untuk belajar dari pengalaman dan pengetahuan hidup 
orang lain yang tertulis di dalamnya. Selain buku-buku rohani, ada baiknya kita juga membaca buku-buku kepribadian sehingga kita terbantu untuk menumbuhkan dan mengembangkan kepribadian kita men-jadi lebih dewasa. Dengan demikian, hidup iman dan kepribadian kita akan berkembang secara seimbang.

\section{Agus Widodo}

Ilmu dan Teologi Patristik di Istitutum Patristicum Augustinianum, Roma. Email: aguswidodo837@gmail.com.

\section{CATATAN AKHIR}

1 Pusat Bahasa Departemen Pendidikan Nasional, Kamus Bahasa Indonesia, (Jakarta, 2008), 1728.

2 K. Prent - J. Adisubrata - W.J.S. Poerwadarminta, Kamus Latin - Indonesia, (Yogyakarta: Kanisius 1969), 347; 876.

3 Gilian Clark, Augustine: The Confessions, (England: Cambridge University Press, 1993), 8

4 Richard Price, Agustinus, (Yogyakarta: Kanisius 2000), 12 .

5 Philip Caraman, Ignatius Loyola: A Biography of the Founder of the Jesuits, (San Francisco: Harper \& Row Publisher 1990), 27.

6 Candido de Dalmases, SJ., Ignatius Loyola: Pendiri Serikat Yesus. Riwayat Hidup dan Karyanya, (Yogyakarta: Penerbit Universitas Sanata Dharma, 2009), 49-53.

7 Candido de Dalmases, SJ., Ignatius Loyola: Pendiri Serikat Yesus. Riwayat Hidup dan Karyanya, 56

8 Candido de Dalmases, SJ., Ignatius Loyola: Pendiri Serikat Yesus. Riwayat Hidup dan Karyanya, 57-61

9 Candido de Dalmases, SJ., Ignatius Loyola: Pendiri Serikat Yesus. Riwayat Hidup dan Karyanya, 61-64

10 St. Teresa of Avila, "The Book of Her Life" dalam Kieren Kavanaugh, OCD., dan Otilio Rodriguez, OCD., (eds.), The Collected Works of St. Teresa of Avila, Vol 1, 38-40

11 Alberto A.Djono Moi, O.Carm., "Edith Stein: Riwayat Hidup dan Karyanya", dalam Edison R.L.Tinambungan, O.Carm., Perempuan Menurut Pandangan Edith Stein, (Malang: Penerbit Dioma 2003), 1-25.

12 Waltraud Herbstrith, Edith Stein: A Biography, (San Francisco: Harper \& Row Publisher 1985), 5-8

13 Alberto A.Djono Moi, O.Carm., "Edith Stein: Riwayat Hidup dan Karyanya”, 21.

14 Marie Adele Dennies, Oscar Romero dan Dorothy Day: Berjalan Bersama Kaum Miskin, (Yogyakarta: Kanisius 2008), 35.
15 Christian Feldmann, Pejuang Keadilan dan Perdamaian, (Yogyakarta: Kanisius 1990), 113.

16 Dennis Q.Mc Inerny, Thomas Merton: The Man and His Work, (Washington: Cirtecian Publications Consortium Press, 1974), 3.

17 Christian Feldmann, Pejuang Keadilan dan Perdamaian, 114.

18 Christian Feldmann, Pejuang Keadilan dan Perdamaian, 127.

19 Al. Purwahadiwardaya, MSF., Pertobatan dalam Tradisi Katolik, 62-67.

20 Tim Redaksi Penerbit Obor, Beberapa Metode Membaca Buku Rohani, Jakarta: Obor 1992, 24.

21 Lawrence Kohlberg, Tahap-Tahap Perkembangan Moral, (Yogyakarta: Kanisius 1995), 56-59.71-73; James W. Fowler, Teori Perkembangan Kepercayaan, (Yogyakarta: Kanisius 1995), 271275.

22 Tim Redaksi Penerbit Obor, Beberapa Metode Membaca Buku Rohani, 26-27.

23 Paulist Press telah menerbitkan seri buku rohani klasik berjudul: "The Classics Western Spirituality" yang terdiri dari 60 jilid

24 Tim Redaksi Penerbit Obor, Beberapa Metode Membaca Buku Rohani, (Jakarta: Obor, 1992), 27.

\section{DAFTAR RUJUKAN:}

Clark, Gilian, Augustine, The Confessions, England: Cambridge University Press, 1993,

Dalmases, Candido de, SJ., Ignatius Loyola: Pendiri Serikat Yesus. Riwayat Hidup dan Karyanya, Yogyakarta: Universitas Sanata Dharma, 2009.

Dennies, Marie Adele, Oscar Romero dan Dorothy Day: Berjalan Bersama Kaum Miskin, Yogyakarta: Kanisius, 2008.

Dickens, Charles, A Christmas Carol, London and Melbourne: Ward, Lock \& Co., Limited, 1843.

Djono Moi, Alberto A., O.Carm., "Edith Stein: Riwayat Hidup dan Karyanya", dalam Edison R.L.Tinam-bungan, O.Carm. (ed.), Perempuan Menurut Pandangan Edith Stein, Malang: Dioma, 2003.

Eko Riyadi, St., Pr., Hidup dalam Kristus. Pengalaman Rohani St. Paulus dalam Peristiwa Damsyik, Yogyakarta: Kanisius, 2008. 
Fowler, James W., Teori Perkembangan Kepercayaan, Yogyakarta: Kanisius, 1995.

Kohlberg, Lawrence, Tahap-Tahap Perkembangan Moral, Yogyakarta: Kanisius, 1995 .

Mc Inerny, Dennis Q., Thomas Merton: The Man and His Work, Washington: Cirtecian Publications Consortium Press, 1974.

Price, Richard, Agustinus, Kanisius, Yogyakarta, 2000.

Purwahadiwardaya, Al., MSF., Pertobatan dalam Tradisi Katolik, Yogyakarta: Kanisius, 2007.
Warisan Paulus bagi Umat. Ajaran Iman, Pastoral, dan Moral, Kanisius, Yogyakarta, 2008.

St. Teresa of Avila, "The Book of Her Life" dalam Kieren Kavanaugh, OCD., dan Otilio Rodriguez, OCD., (eds.), The Collected Works of St. Teresa of Avila, Volume I

Suharyo, I. Mgr., Menjadi Manusia Dewasa: Belajar dari Pengalaman Hidup St. Paulus, Yogyakarta: Kanisius, 1999.

Tim Redaksi Penerbit Obor, Beberapa Metode Membaca Buku Rohani, Jakarta: Obor, 1992. 